\title{
Incidentally Discovered Extensive Squamous Metaplasia within Borderline Phyllodes Tumor: Presentation of a Rare Tumor
}

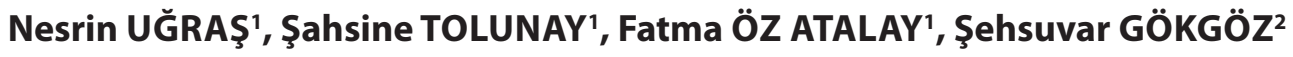

Department of ${ }^{1}$ Pathology and ${ }^{2}$ General Surgery, Uludağ University, Faculty of Medicine, BURSA, TURKEY

\begin{abstract}
Phyllodes tumors are uncommon biphasic fibroepithelial neoplasms of breast, comprising less than $1 \%$ of all breast neoplasms. We therefore aimed to present the case with its microscopic findings. In this article, we report a 59-year-old female admitted to the general surgery department with a rapidly, enlarging, palpable mass in right breast. After histopathological examination, it was diagnosed as borderline phyllodes tumor with extensive squamous metaplasia. Metaplastic changes are infrequent in the stromal and epithelial component of these tumors. Extensive squamous metaplasia within phyllodes tumor is rare and may occur in benign, borderline and malign subtypes.
\end{abstract}

Key Words: Breast neoplasm, Phyllodes tumor, Metaplasia

\section{INTRODUCTION}

Phyllodes tumors (PTs) are uncommon fibroepithelial tumors, composing approximately $1 \%$ of breast tumors and form $2 \%-3 \%$ of all breast fibroepithelial lesions (1). These tumors are biphasic breast neoplasms showing projections of cellular stroma covered by epithelium and myoepithelium into epithelial-lined cystic spaces and creating a leaf-like appearance (2). In the stromal and epithelial component, metaplastic change is infrequent. Cartilaginous, osteoid and lipomatous metaplasia sometimes can occur in the stroma of PTs. However, in the lining epithelia, apocrine and squamous metaplasia can occasionally be seen. Rarely, ductal or lobular carcinoma in situ, invasive carcinoma may arise in the epithelial component (3).

Herein, we presented a case of borderline phyllodes tumor with extensive squamous metaplasia, and reviewed the literature regarding suggested mechanisms for its etiology.

\section{CASE REPORT}

A 59-year-old female was admitted to the general surgery department with a rapidly, enlarging, palpable mass in right breast. Physical examination showed a palpable, mobile mass $3,5 \mathrm{~cm}$ in diameter below the nipple of right breast that was not fixed to overlying skin and surrounding tissues. Mammography showed a mass with cystic area and partially irregular borders separated from the adjacent

(Turk Patoloji Derg 2016, 32:47-50)

Received : 16.01.2012 Accepted : 02.03.2012 breast. Sonography revealed a $4 \times 3 \mathrm{~cm}$ measuring, smooth bordered, lobulated lesion. Ultrasound-guided percutaneous biopsy was performed on this breast mass and pathologic examination showed fibroepithelial lesion. For definitive diagnosis surgical assessment and excisional biopsy are recommended. Macroscopically, the resected specimen was $6 \times 5.5 \times 4 \mathrm{~cm}$ in size and the cut surface showed smooth bordered pale-tan mass, measured $4 \times 3.5 \mathrm{~cm}$, which had a whorled appearance. Histologically, leaf-like structures characterized areas with increased stromal component were observed. The cells of stromal component showed minimal or moderate atypia. Five to six mitotic figures per 10 highpower fields (HPF) were counted in the cellular areas of the stromal component. Cellular stroma enclosing glandular and cystic spaces lined by multilayered squamous cells without evidence of atypical changes was also noted (Figure 1). The cystic spaces filled with laminated keratin material (Figure 2). Estrogen receptor (Figure 3) and progesterone receptor (Figure 4) was strongly expressed in the epithelial component. Ki67 proliferative index in the stromal component was $22 \%$ (Figure 5). By these histopathological and immunohistochemical findings, the case was diagnosed as borderline phyllodes tumor with cystic squmaous metaplasia. The patient was treated by adjuvant radiotherapy and hormonotherapy. Follow-up after one year showed no evidence of recurrence or metastasis. Axillary lymphadenopathy was not identified at one-year follow-up.

Correspondence: Nesrin UĞRAŞ

Uludağ Üniversitesi, Tip Fakültesi, Patoloji Anabilim Dalı, BURSA, TURKEY

E-mail: nesrin_ugras@yahoo.com Phone: +90 2242953680 


\section{DISCUSSION}

Phyllodes tumors (PT) is a rare fibroepithelial neoplasm of the breast, which can grows rapidly and create asymmetry of the breast (4). These tumors rarely show aggressive behavior. Clinically, patients present with mobile masses having smooth borders. On histopathological examination, characteristic findings of PTs are stromal hypercellularity and a prominent intracanalicular growth pattern (5). Cleft-like spaces and ducts are lined by two layered, ductal epithelium in the inner surface and myoepithelial cells of outward. PT is usually classified as benign, borderline or malignant, according to histologic features, which are the presence of stromal overgrowth, cellularity, margin status and mitotic figure count in stromal cells (5-8). The most commonly used parameter to classifying PT is mitotic figure counts (4). If the number of mitotic figures is less than 4/10 HPF PT is classified as benign, however if there are more than 10 mitoses/10 HPF, the tumor is considered having malignant potential. A borderline PT represents intermediate microscopic findings (9). In current case, 5-6/ HPF mitotic figures were counted, revealing a borderline subtype.

In the stromal and epithelial components of PT metaplastic change is rare. In one of the reported PT series, stromal metaplasia that included adipose and chondromyxoid

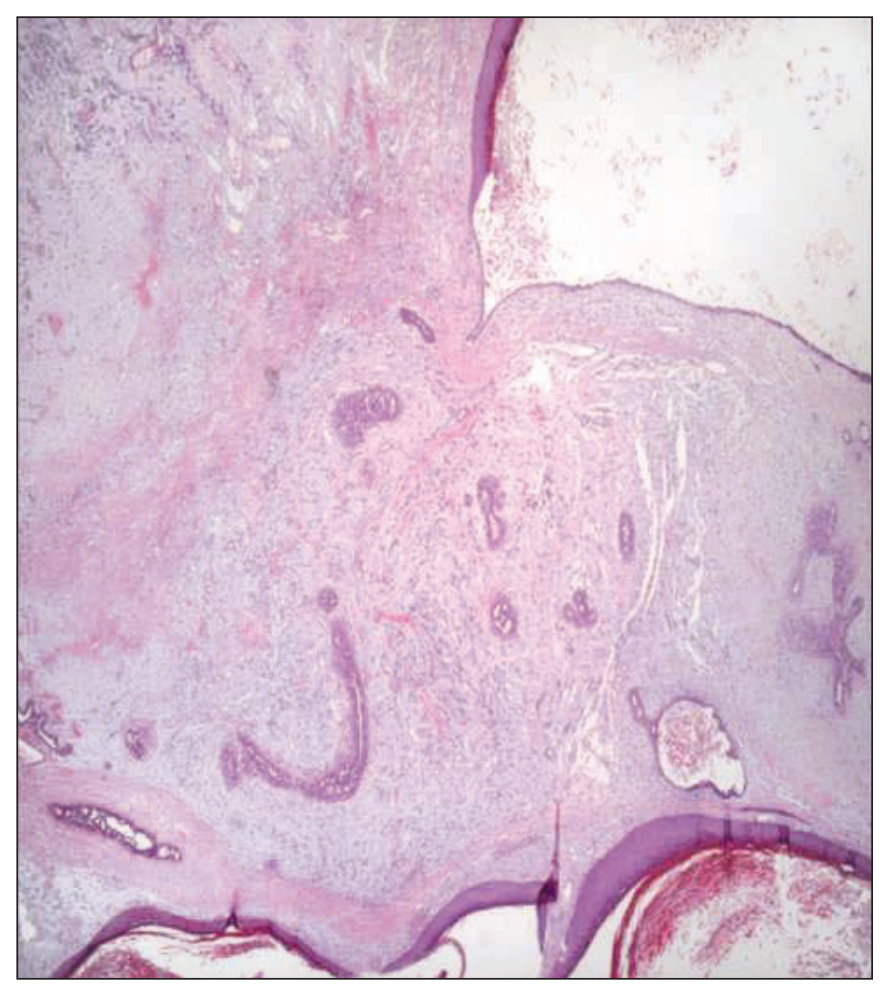

Figure 1: Squamous metaplasia within borderline phyllodes tumor: Presence of multilayered squamous cells (H\&E; x100).

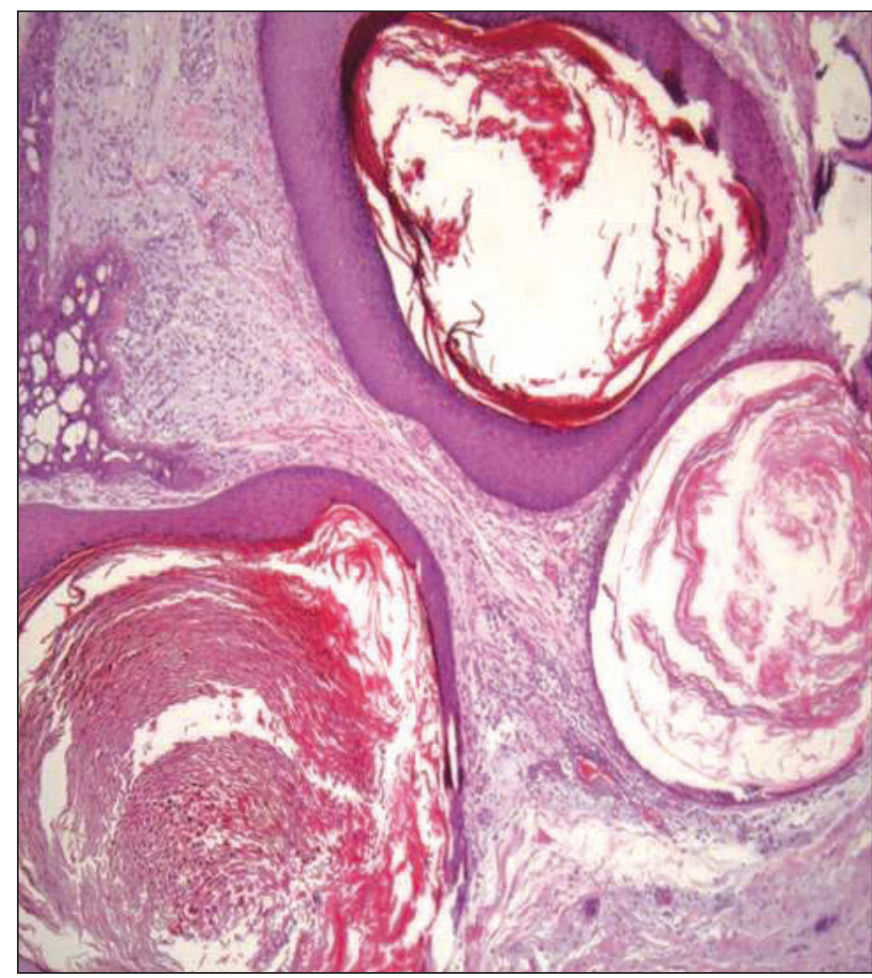

Figure 2: Squamous metaplasia within borderline phyllodes tumor: Presence of cystic spaces filled with keratin material (H\&E; x200).

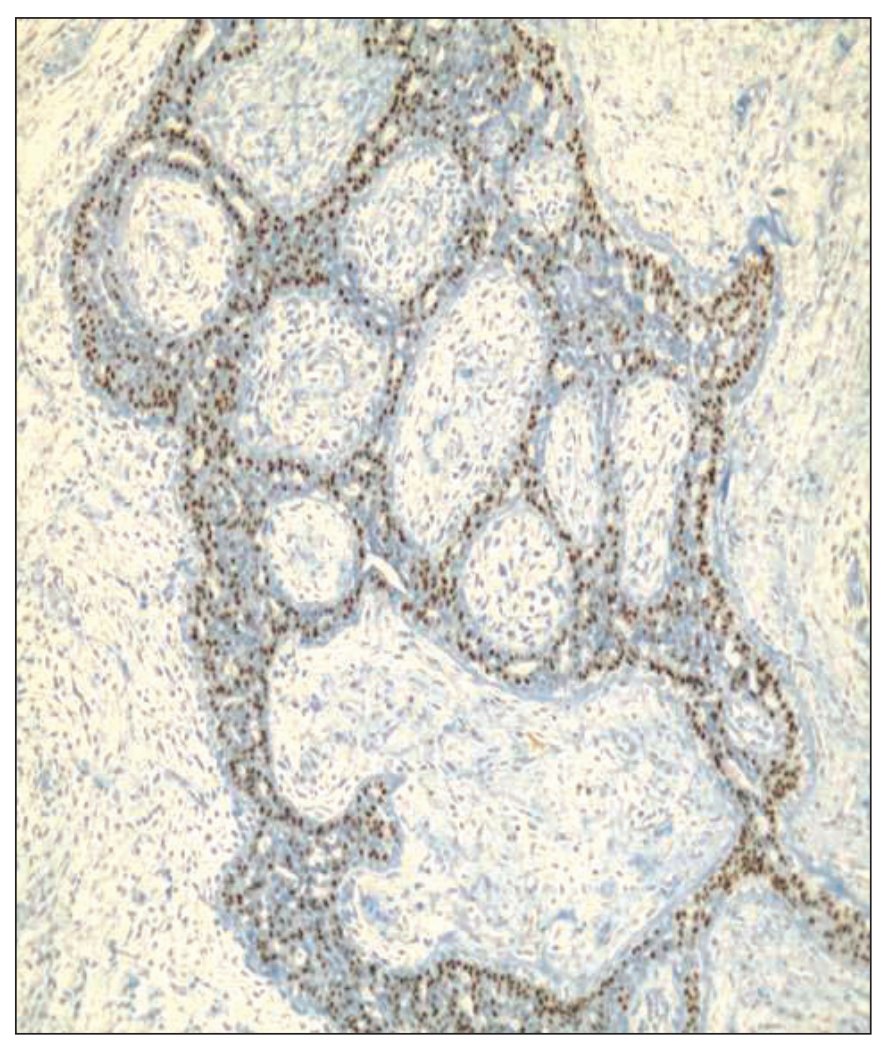

Figure 3: Estrogen receptor expressed in epithelial component (ER; x400). 


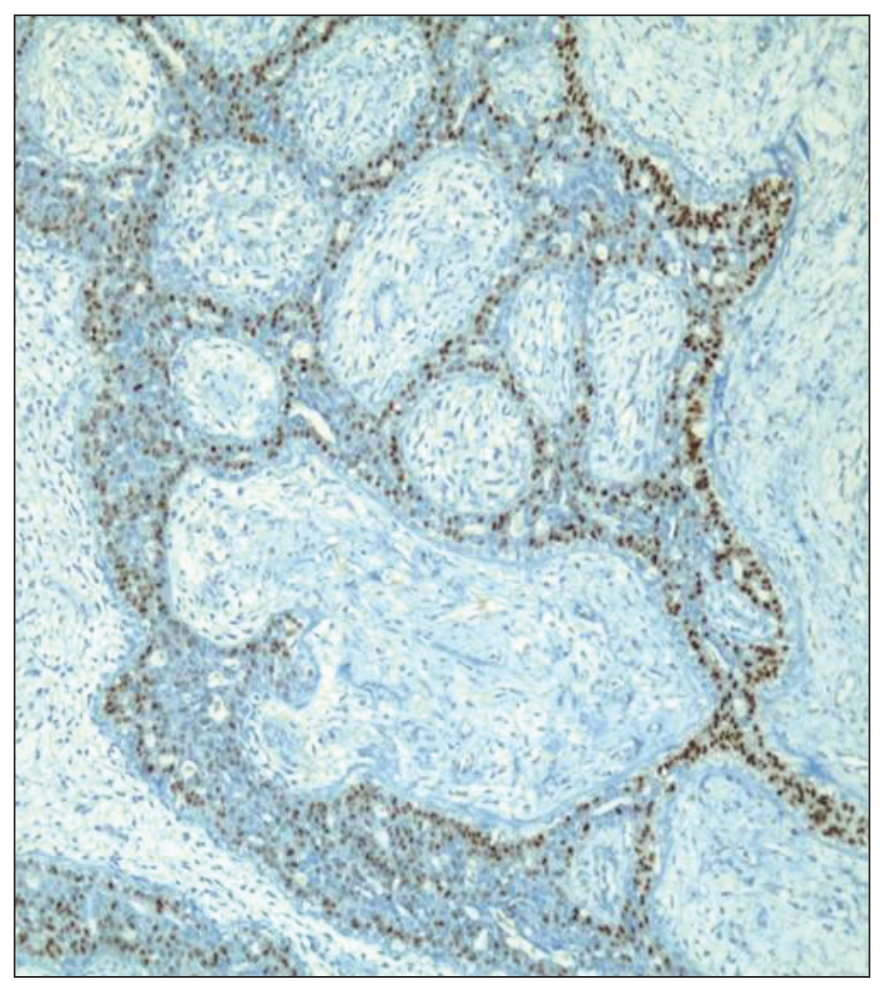

Figure 4: Progesterone receptor expressed in epithelial component (PR; x400).

elements, malignant heterologous components, such as osteosarcoma, rhabdomyosarcoma and liposarcoma was presented in only $11(3.3 \%)$ of 335 cases. The epithelial component may show a variety of appearances. Varying degrees of usual-type epithelial hyperplasia was well recognized in PT and epithelial squamous metaplasia was observed in 12 cases (3.6\%), 5 of which revealed squamous cysts (10). Apocrine metaplasia had been also reported in the epithelium of PTs $(7,11)$. Squamous metaplasia of ductal epithelium, which occurs in benign, malignant and borderline PTs, like our case, was found in about $10 \%$ of PTs (3). Examination of cystic areas of squamous metaplasia by aspiration may lead to a mistaken diagnosis of a squamous cyst (12). Excluding PTs, extensive squamous metaplasia in breast as much as seen in our case had been reported only in the epithelium of gynecomastia (13) and benign breast papillomatosis (14).

The development of squamous metaplasia in breast may be similar to squamous lesions that are seen in the salivary gland and the uterine cervix. The squamous change in the breast was suggested to begin within the myoepithelial cell layer, before eventually involving the entire acinus. $(15,16)$. This myoepithelial origin of the metaplastic squamous cells was supported by the immunohistochemical studies,

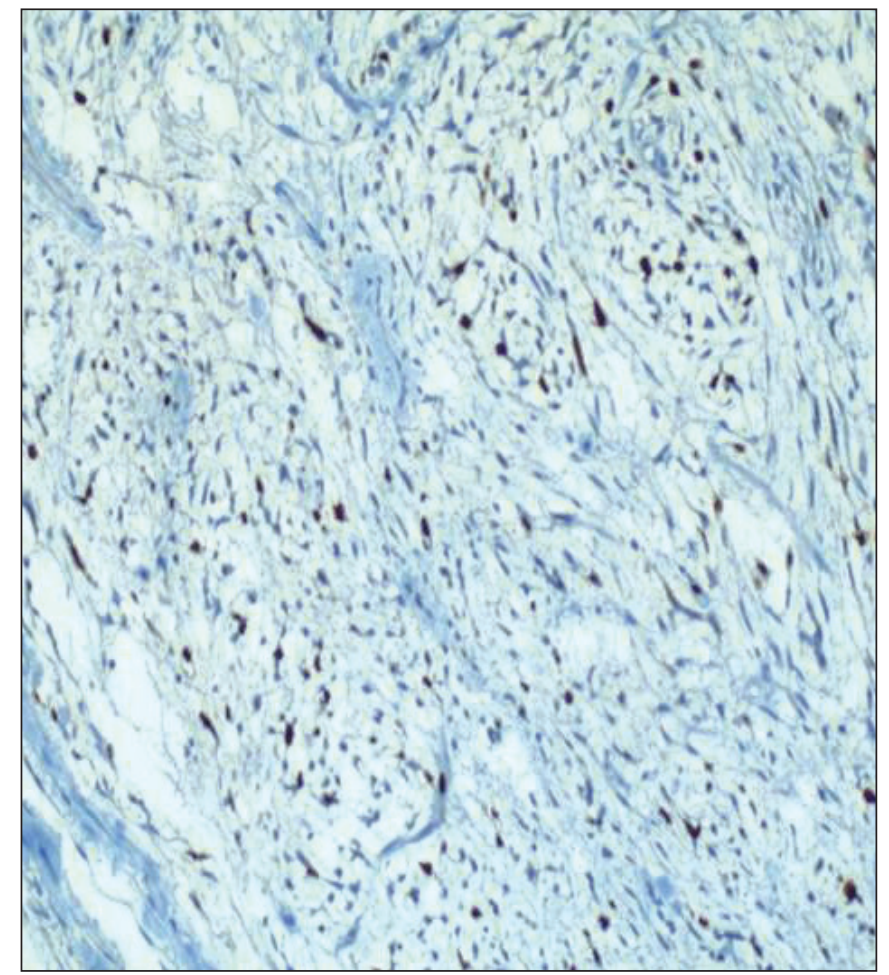

Figure 5: Ki67 proliferative index in stromal component (Ki-67; $\mathrm{x} 400)$.

showing actin, vimentin, S-100 protein expression of metaplastic squamous cells (17).

In conclusion, as reported in current case, extensive cystic squamous metaplasia is a rare feature in phyllodes tumors.

\section{REFERENCES}

1. Quinlan-Davidson S, Hodgson N, Elavathil L, Shangguo T. Borderline phyllodes tumor with an incidental invasive tubular carcinoma and lobular carcinoma in situ component: A case report. J Breast Cancer. 2011;14:237-40.

2. Schnitt SJ, Collins LC. Fibroepithelial lesions. In: Schnitt SJ, Collins LC editors. Biopsy interpretation of the breast. Philadelphia:Lippincott Williams \& Wilkins; 2009.166-78.

3. Rosen PP. Fibroepithelial neoplasms. In: Rosen PP editor. rosen's breast pathology. 3rd edition, Philadelphia:Lippincott Williams\&Wilkins; 2009.202-17.

4. Sugie T, Takeuchi E, Kunishima F, Yotsumoto F, Kono Y. A case of ductal carcinoma with squamous differentiation in malignant phyllodes tumor. Breast Cancer. 2007;14:327-32.

5. Bellocq JP, Mango G: Fibroepithelial tumors. In: Tavassoli FA, Devilee P. editors. Pathology and genetics: Tumors of the breast and female genital organs. Lyon: IARC Press; 2003.99-103.

6. Ward RM, Eurans HL. Cystosarcoma phyllodes. A clinicopathologic study. A clinicopathologic study of 26 cases. Cancer. 1986;58:2282-9. 
7. Grimes MM. Cystosarcoma phyllodes of breast: Histologic features, flow cytometric analysis, and clinical correlations. Mod Pathol. 1992;5:232-9.

8. Tse GMK, Tan PH. Recent advances in the pathology of fibroepithelial tumours of the breast. Current Diag Pathol. 2005;11:426-34.

9. Pandey M, Mathew A, Kattoor J, Abraham EK, Mathew BS, Rajan B, Nair KM. Malignant phyllodes tumor. Breast J. 2001;7:411-6.

10. Tan PH, Jayabaskar T, Chuah KL, Lee HY, Tan Y, Hilmy M, Hung $\mathrm{H}$, Selvarajan S, Bay BH. Phyllodes tumors of the breast: The role of pathologic parameters. Am J Clin Pathol. 2005;123:529-40.

11. Salisbury JR, Singh LN. Apocrine metaplasia in phyllodes tumours of the breast. Histopathology. 1986;10:1211.

12. Agarwal J, Kapila K, Verma K. Phyllodes tumor with keratin cysts: A diagnostic problem in fine needle aspiration of the breast. Acta Cytol. 1991;35:255-6.
13. Gottfried MR. Extensive squamous metaplasia in gynecomastia. Arch Pathol Lab Med. 1986;110:971-3.

14. Söderstrom KO, Toikkanen S. Extensive squamous metaplasia simulating squamous cell carcinoma in benign breast papillomatosis. Hum Pathol. 1983;14:1081-2.

15. Reddick RL, Jennette JC, Askin F. Squamous metaplasia of the breast. An ultrastructural and immunologic evaluation. Am J Clin Pathol.1985;84:530-3.

16. Devi PM, Singh LR, Gatphoh ED. Fibroadenoma with squamous metaplasia. Singapore Med J. 2007;48:682-3.

17. Raju GC. The histological and immunohistochemical evidence of squamous metaplasia from the myoepithelial cells in the breast. Histopathology. 1990;17:272-5. 